\title{
IMPLEMENTING INCREMENTAL SHEET METAL Forming ON A CNC MACHINING CENTRE
}

\author{
Antonio Calvino ${ }^{\mathrm{a}}$, Asuncion Rivero ${ }^{\mathrm{b}}$, Miguel Álvarez, \\ Francisco Puerta $^{\mathrm{a}}$, Jorge Salguero ${ }^{\mathrm{a}}$, Mariano Marcos $^{\mathrm{a}}$ \\ ${ }^{a}$ University of Cadiz, Faculty of Engineering. Mechanical Engineering and Industrial Design Dept. Av. Universidad de \\ Cádiz 10, E-11519 - Puerto Real, Cádiz, Spain \\ ${ }^{b}$ Fundacion Tecnalia Research \& Innovation. Scientific and Technological Park of Guipuzkoa. Paseo Mikeletegui 7, E- \\ 20009, Donostia-San Sebastián (Guipuzkoa), Spain
}

\begin{abstract}
Incremental Sheet Forming (ISF) process emerges as an alternative to classic shaping processes. Two variants of the ISF process are used: negative forming or SPIF (Single Point Incremental Forming), in which it is not necessary using a die; and positive forming or TPIF (Two Point Incremental Forming).

ISF is usually performed on specifically designed machines controlled by $\mathrm{CNC}$ or in retrofitted CNC milling machines. However, in the most of cases, the possibility of combining milling and ISF is not considered.

This paper is focused on a study about the implementation of ISF process in a CNC machining center through the specific design of the clamping tools. So, it is not necessary to retrofit the machining center and it is possible to think about combining both processes in multitask operations.
\end{abstract}

Keywords: Incremental Sheet Forming; CNC; clamping; tooling design.
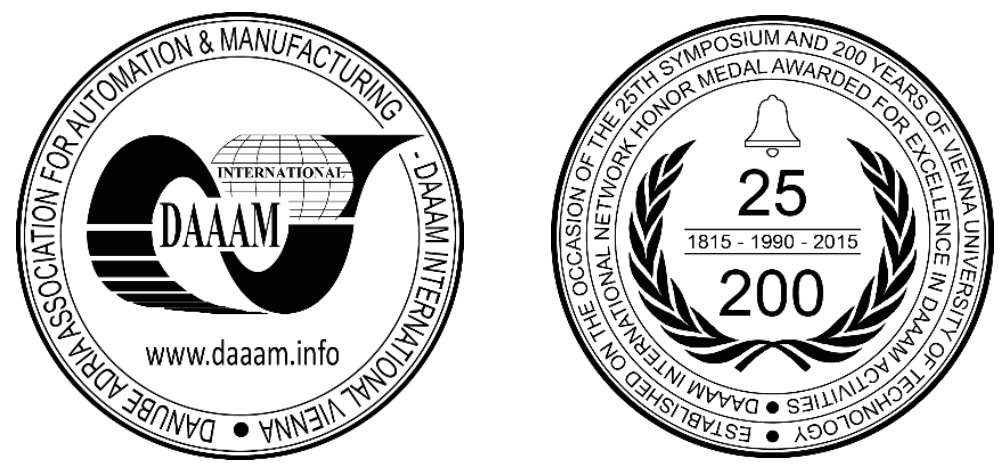

This Publication has to be referred as: Calvino Fernandez-Trujillo, A[ntonio]; Rivero, A[suncion]; Alvarez, M[iguel]; Puerta, F[rancisco] J[avier]; Salguero, J[orge] \& Marcos, M[ariano] (2016). Implementing Incremental Sheet Metal Forming on a CNC Machining Centre, Proceedings of the 26th DAAAM International Symposium, pp.0926-0929, B. Katalinic (Ed.), Published by DAAAM International, ISBN 978-3-902734-07-5, ISSN 1726-9679, Vienna, Austria DOI: 10.2507/26th.daaam.proceedings.129 


\section{Introduction}

Driven by the increasing competitiveness within the automobile and aerospace sectors, sheet-forming processes have experienced severe changes in the last decades. In the past, press forging was the most widely used sheet-forming process. This manufacturing strategy involves the use of two dies to form the flat metal sheet into the desired final shape. The unavoidable manufacture of these dies makes press forging economically feasible only for the production of very large product batches. Nevertheless, now Rapid Prototyping is becoming increasingly important, as a solution to cope with the more actual demand of testing new parts or products. In fact, manufacturing a small and discrete number of metal parts is in many occasions the most convenient route to validate new products $[1,2]$.

In this new context, Asymmetric Incremental Sheet Metal Forming (AISF) is consolidating as one of the most promising plastic forming processes to manufacture in a fast way small batches of sheet products from a variety of metallic alloys (e.g. aluminium, titanium or steels) [1]. The term fast is not referred to a short total manufacturing time for each part but, instead, to the short elapsed time between the CAD/CAM design and the beginning of the manufacturing step $[3,4]$. Thus, in contrast to press forging, AISF allows manufacturing the metal part prototype just immediately after defining the required tool trajectories. Moreover, overcoming the need to prepare, with high accuracy, the pressing dies allows also decreasing the production costs and performing rapid prototyping. Therefore, AISF appears as a very suitable manufacturing approach for innovation and development of new products. Two variants of the ISF process are used: negative forming or SPIF, in which it is not necessary using a die; and positive forming or TPIF, where other dies are usually used $[1,5,6]$.

Currently, a very limited number of machines specifically designed to apply AISF are commercially available [7]. The investment related to the acquisition of this particular type of equipment, which strongly counterbalances the savings that result from avoiding the use of dyes, is slowing down the establishment of this innovative manufacturing method [5,8]. Implementing AISF in an already available CNC machine centre appears as an interesting approach to overcome this limitation. This does not only allows diversifying the machining strategies available on this type of more widely spread instruments but also opening novel machining techniques which combine material removal and deformation steps. This finally provides an extra flexibility to the original CNC machine [7,9,10].

Previous works have already reported the application of AISF on CNCs. As an illustration, J. Kopac and Z. Kampus have reported the use of a CNC milling machine-tool Mori Seiki [2]. On its hand, Malwad et al. have analysed the details of the deformation mechanisms during Single point AISF on AA8011 aluminium alloy sheets using a 3 axis HAAS CNC Milling Machine [5]. Likewise, R. Ben Hmida et al. have investigated the influence of the initial grain size of FPG copper foils on the material behaviour during SP AISF using a 3-axis CNC vertical milling machine [6].

The design of the metal sheet clamping tools is one of the necessary steps to implement AISF on CNCs. The specific characteristics of these tools will result key for the final performance of the adapted machine. This contribution focuses specifically on this aspect. In particular, two alternative designs for this clamping tool is presented which allow fast customization of the working area and which is easily adaptable to different metal sheets formats. Additionally, the manufacture of a prototype of this clamping tool using 3D printing is also presented.

The proposed design refers to a teaching-oriented CNC milling centre. Therefore, the dimensional and operational parameters employed here may differ from others corresponding to CNC equipment used for industrial purposes.

\section{Methodology}

The CNC machine adapted in this work was an ODISEA from Alecop SC, Figure 1(a). Table 1 includes its most relevant technical features. CAD design of the proposed tools was performed using the Dassault System Software "CATIA V5R20". The corresponding PLA prototypes were further prepared on a Cubex 3D printer, Figure 1(b). For the manufacture of the prototypes, the 3D printer parameters previously optimized in $[11,12,13]$ were employed.

Finally, let us mention that the corresponding ISF tool to be used with the CNC machine here adapted was manufactured by grinding on a WC-Co bar.

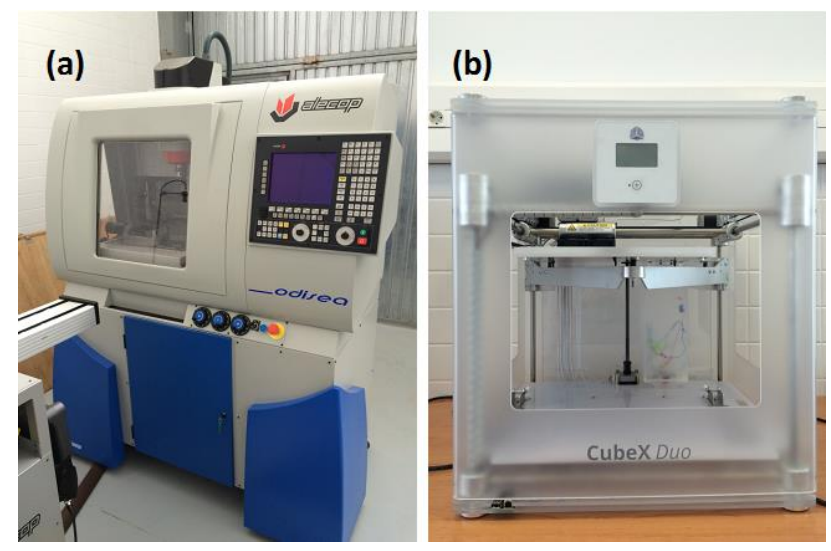

Fig. 1. A general view of: (a) ODISEA CNC Milling Center; (b) CubeX Duo 3D Printer. 


\begin{tabular}{lc}
\hline \multicolumn{2}{c}{ Head tool } \\
\hline Turning speed & 100 to $4000 \mathrm{rpm}$ \\
Motor & Triphasic Asynchronous (1.5 Kw) \\
Max. Torque & 7 N*m at 2000 rpm \\
Principal axis inner cone & DIN 69871-B (ISO-30) \\
\hline \multicolumn{2}{c}{ Working area } \\
\hline Head-to-Table max. distance & $320 \mathrm{~mm}$ \\
Axis-to-column distance & $340 \mathrm{~mm}$ \\
X axis path length & $200 \mathrm{~mm}$ \\
Y axis path length & $200 \mathrm{~mm}$ \\
\hline
\end{tabular}

Table 1. Technical features of the adapted CNC machine.

\section{Results}

The major constrains considered for the design of the clamping tool were the maximum dimensions available as working area, the maximum length of the path along the $\mathrm{X}$ and $\mathrm{Y}$ axis which limit the characteristics of the tool trajectories and the maximum distance between the ISF tool tip and the working table. We have also considered that all the necessary metallic parts involved in the design can be manufactured in fact using the CNC milling machine adapted.

Figure 2 shows isometric views of the proposed CAD design solutions, considering $100 \mathrm{x} 100 \mathrm{~mm}$ and $100 \mathrm{x}$ $200 \mathrm{~mm}$ formats for the metal blanks. The first part of the clamping tool consists of a rectangular-shaped support plate (1), which is fixed to the working table by screws at each of its corners. An array of regularly distributed holes, 3 x 5 in Figure 2, are drilled into this basement plate. Screws inserted from the bottom face of the plate will allow further anchoring of columns (2) onto the top face. Decreasing the pitch between neighbouring holes allows a more flexible customization of the blank dimensions.

Each of the four thick columns is threaded on its two bases so as to allow being tightly fixed to both the support plate and the lower pressing plate (3). The metal blank to be formed by AISF is kept locked by pressing it between two, upper (4) and lower (3), pressing plates. Up to eight screws uniformly distributed along the rim of the pressing plates allow a tight fixation of the metal blank, which will be kept fix at any time during the AISF procedure.
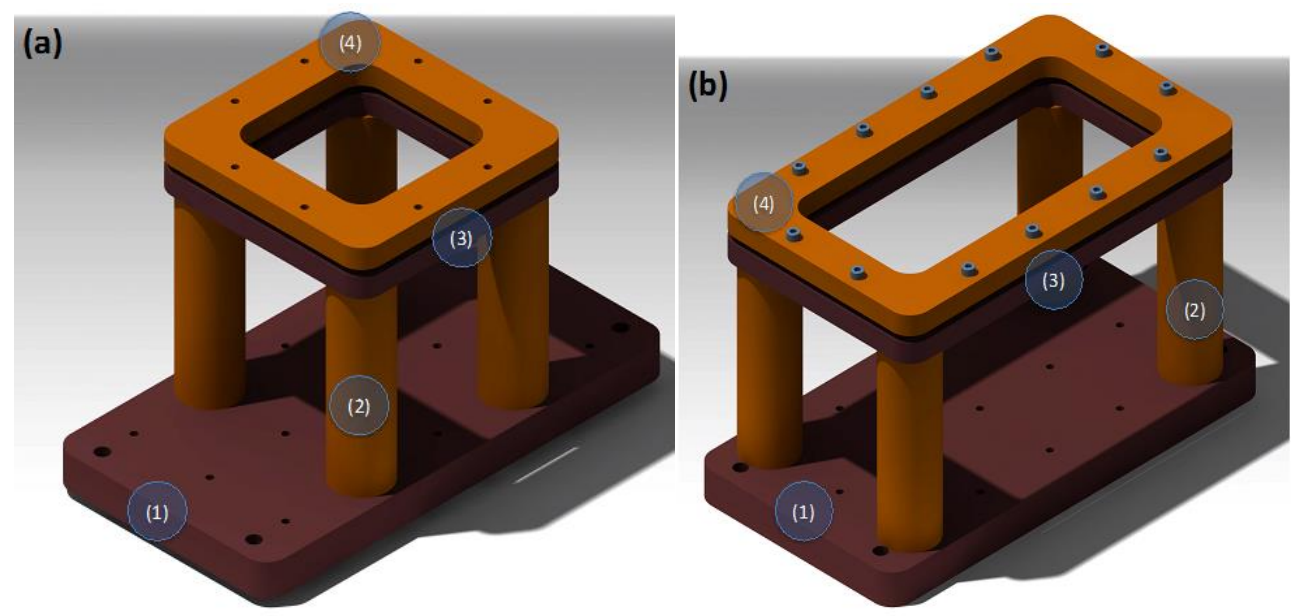

Fig. 2. Isometric views of the CAD designs of two possible configurations of the designed clamping tool for two different metal blank formats: (a) $100 \times 100 \mathrm{~mm}$; (b) $200 \times 100 \mathrm{~mm}$.

Nevertheless, to ensure a better clamping, lateral shifts of the metal blank are avoided. In order to facilitate its centring, the lower pressing plate was flanged reducing its thickness, by $0.5 \mathrm{~mm}$, up to $1 \mathrm{~mm}$ from the inner edge. This clamping tool can be manufactured in an aluminium alloy to make it lighter.

Additionally, a partial or complete die can be fixed by screwing onto the upper part of the support plate in case that two point incremental forming is to be carried out.

Let us finally mention PLA prototypes of all the parts involved in this design were manufactured by 3D printing. Figure 3 shows a general view of all these parts both as separated items (a), after assembling them into the final clamping tool design (b), and mounting it on the ODISEA CNC milling centre (c). Numbers in Figure 3 correspond with the same parts on Figure 2. An ISF tool designed to operate in the adapted CNC centre was manufactured, and is shown as item 5 in Figure 3 (a). 

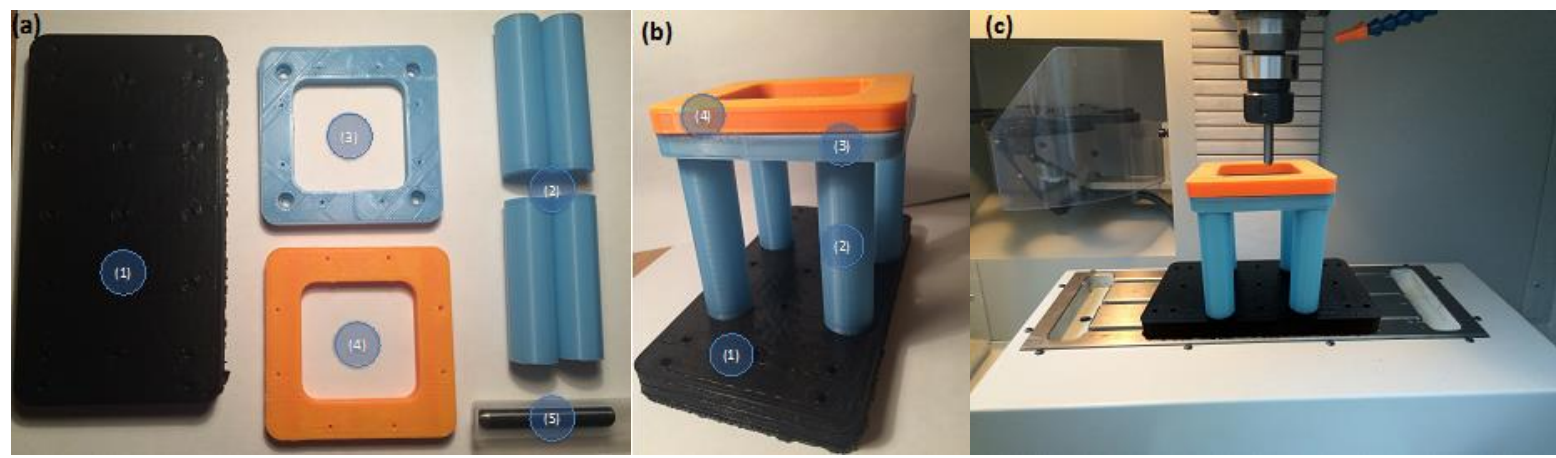

Fig. 3. PLA prototypes of all the parts involved: (a) separated items; (b) Assembly of the ISF clamping tool; (c) Mount of the ISF clamping tool on ODISEA CNC milling center.

\section{Conclusions}

A design is proposed for a clamping tool that allows implementing AISF on an ODISEA CNC milling centre in a flexible way. With this design SPIF can be combined with other machining operations, like drilling or milling, at the end of the deformation step, thus improving the flexibility of the $\mathrm{CNC}$ machine. The proposed design can be manufactured in an aluminium alloy.

In case this design should be transferred to a CNC centre with industrial production purposes aimed at the production of metal parts of larger dimensions, the number of columns supporting the upper and lower pressing plates should be increased, in order to provide a higher stiffness to the clamping tool. By doing so, a higher stability during the AISF process would be guaranteed.

As a further improvement to the design described in this paper, we intend to implement a translation system along the Z-axis of the supporting columns, to synchronize the path followed by the tool with the movement of the clamping tool. This would allow achieving more complex shapes during the ISF process.

\section{Acknowledgements}

The UE (Project COSSTA), the Andalusian Government (PAIDI) and from Fundacion Tecnalia R\&I (through the CATEDRA TECNALIA of the UCA) have provided financial support to this work.

\section{References}

[1] W.C. Emmens, G. Sebastiani, A.H. van den Boogaard, The technology of Incremental Sheet Forming-A brief review of the history. J. Mat. Proc. Tech. 210 (2010) 981-997.

[2] J. Kopac, Z. Kampus, Incremental sheet metal forming on CNC milling machine-tool, J. Mat. Proc. Tech. 162-163 (2005) 622-628

[3] Rozmarina Dubovska, Jaroslav Jambor, Jozef Majerik, Implementation of CAD/CAM system CATIA V5 in Simulation of CNC Machining Process, Proc. Eng. 69 (2014) 638 - 645, 24th DAAAM, 2013.

[4] Jozef Majerik, Jaroslav Jambor, Computer Aided Design and Manufacturing Evaluation of Milling Cutter when High Speed Machining of Hardened Steels, Proc. Eng. 100 (2015) 450 - 459, 25th DAAAM, 2014.

[5] D. S. Malwad, Dr. V. M. Nandedkar, Deformation Mechanism Analysis of Single Point Incremental Sheet Metal Forming. Proc. Mat. Sci. 6 (2014) $1505-1510$.

[6] R. Ben Hmida, S., Influence of the initial grain size in single point incremental forming process for thin sheets metal and microparts: Experimental investigations, Mat. and Design 45 (2013) 155-165.

[7] Masaaki Amino, Masashi Mizoguchi, Yuji Terauchi, Trent Maki, Current status of “Dieless” Amino's incremental forming, Proc. Eng. 81 (2014) $54-62$.

[8] T.Madeira, C.M.A.Silva, M.B.Silva, P.A.F.Martins, Failure in single point incremental forming, Int. J. Adv. Manuf. Techol. (2015) 80:1471-1479.

[9] Yanle Li, Haibo Lu, William J. T. Daniel, Paul A. Meehan, Investigation and optimization of deformation energy and geometric accuracy in the incremental sheet forming process using response surface methodology, Int. J. Adv. Manuf. Technol. (2015) 79:2041-2055.

[10] Holger Voswinckel, Markus Bambach, Gerhard Hirt, Improving geometrical accuracy for flanging by incremental sheet metal forming, Int. J. Mat. Form. (2015) 8:391-399.

[11] Matej Paulic, Tomaz Irgolic, Joze Balic, Franc Cus, Andrej Cupar, Tomaz Brajlih, Igor Drstvensek, Reverse Engineering of Parts with Optical Scanning and Additive Manufacturing, Proc. Eng. 69 (2014) 795 - 803, 24th DAAAM, 2013.

[12] A.P. Valerga, M. Batista, R. Bienvenido, S.R. Fernández-Vidal, C. Wendt, M. Marcos, Application of Reverse Engineering and Additive Manufacturing Techniques to Cutting Tools Redesign, Proc. of the 6th Man. Eng. Soc. Int. Conf., Barcelona, Spain, 2015.

[13] C. Wendt, M. Batista, E. Moreno, A.P. Valerga, S.R. Fernández-Vidal, M. Marcos, Preliminary design and analysis of tensile test samples developed by Additive Manufacturing, Proc. of the 6th Man. Eng. Soc. Int. Conf., Barcelona, Spain, 2015. 